\title{
Drug industry dress-up
}

\author{
Deadly Medicines and Organised \\ Crime: How big pharma has \\ corrupted healthcare \\ Peter C. Gøtzsche \\ Radcliffe Medical Press Ltd.; 2013
}

$\mathrm{P}$ hysicians who sometimes call too stridently for reform can go too far in inciting their colleagues to action, bringing to mind the Hungarian obstetrician Ignaz Semmelweis who famously castigated his obstetric colleagues in Vienna in the 1840 s, calling them carriers of "cadaverous particles" and accusing them of killing patients. When proselytizing with such ferocity, instead of being listened to, highly vocal reformers are derided, or worse, ignored.

This is a danger faced by Dr. Peter Gøtzsche, whose new book, Deadly Medicines and Organised Crime: How big pharma has corrupted healthcare, doesn't contain an ounce of sugarcoating. Gøtzsche, a Danish physician and head of the Nordic Cochrane Centre in Copenhagen, has a reputation for telling it as it is, yet it's difficult to criticize his exposure of the dark side of the pharmaceutical industry despite redlining the outrage-o-metre.

Gøtzsche has witnessed the pharmaceutical industry up close, working both as a salesman and scientist before becoming a critic of bias in medicine.

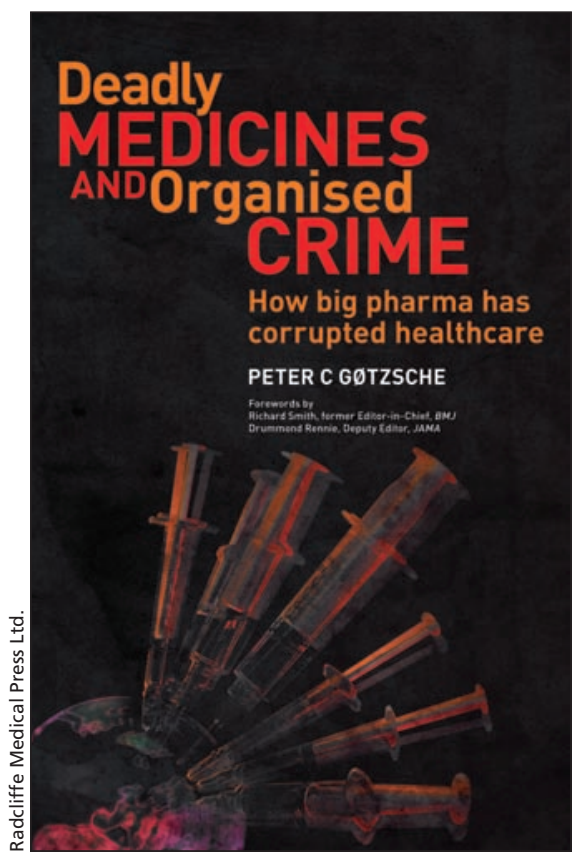

wealthy, uses that wealth strategically to influence prescribing from almost every conceivable angle. Gøtzsche writes that "virtually everything we know about drugs is what the [pharmaceutical] companies have chosen to tell us and our doctors."

Deadly Medicines doesn't just indict the behaviour of the world's major pharmaceutical companies. In dozens of pages of references, Gøtzsche documents their lengthy rapsheets, including kickbacks, threats, intimidation, extortion, fraud, buying

\section{Virtually everything we know about drugs is what the [pharmaceutical] companies have chosen to tell us.}

He writes that, although our doctors are very knowledgeable about such topics as human physiology, "they know very, very little about drugs that hasn't been carefully concocted and dressed up by the drug industry." No doubt the global pharmaceutical industry, being gargantuan and incredibly politicians, pressuring bureaucrats and health policy-makers, as well as corrupting doctors, specialists and patient groups (stuff typically associated with the Mafia).

Gøtzsche's writing is frequently funny, sometimes accidently so. English is not his native tongue, so there is some unusual syntax, such as the adverb "bullshittingly," referring to the manner in which one pharmaceutical company described its product. When referring to a 2012 guideline produced by the Association of the British Pharmaceutical Industry to promote collaboration with doctors, Gøtzsche says he has never seen "so much bullshit and lies crammed into one place before." This document, endorsed by the British Medical Association, the Royal College of General Practitioners and other agencies (that should know better), contends that the "industry plays a valid and important role in the provision of medical education." Gøtzsche argues that this endorsement is just a further example of corruption.

Many will find Gøtzsche's writing glib and overly provocative, but few will be able to counter the facts regarding what Gøtzsche calls a "general system failure," where prescribed drugs rank as the third leading cause of death and their misuse and overuse are capable of killing people on a "horrific scale."

Like Semmelweis, Gøtzsche and many others are calling for a sanitary revolution. He maintains that the very basis of health care has been corrupted - in his words, "like a cancer that has grown uncontrollably." His solution? "We need to stop this."

Despite the confrontational title and thesis, Gøtzsche might be setting a trend among drug-industry commentators who have given up dispensing the niceties and caveats that typically fill many texts about the pharmaceutical industry. His plea to doctors is a simple one that is unarguable: stop being bribed and seduced by organized crime.

\section{Alan Cassels MPA \\ Drug-policy researcher and author University of Victoria \\ Victoria, BC}

CMAJ 2014. DOI:10.1503/cmaj.131799 